\title{
Project leaders' control resources and role overload as predictors of project success: developing the job demands-resources model
}

\author{
Kai-Kristina Lattrich ${ }^{1,2}$ (D) Marion Büttgen ${ }^{1}$
}

Received: 24 August 2018/Accepted: 9 May 2020/Published online: 22 May 2020

(C) The Author(s) 2020

\begin{abstract}
Drawing on the job demands-resources model (JD-R model), this article introduces information control and team control as project leader-specific job resources, as well as role overload as a demand, and then examines their influences on project experience appraisals and project success. With a sample of 185 project leaders, this study reveals that all three factors drive project success and project leader well-being. The moderating effects of role overload on the relationships between team control and negative experience and between team control and goal attainment are particularly remarkable; goal attainment is highest with high team control and high role overload. Similarly, the most positive experiences occur with high team control and high role overload. This further development of the JD-R model, thus, identifies information and team control as resources specific to project leaders and role overload as a predominant challenge stressor, with an ambivalent nature.
\end{abstract}

Keywords Temporary organization $\cdot$ Project leader $\cdot$ Job demands-resources model $\cdot$ Control $\cdot$ Challenge stressors $\cdot$ Role overload

\section{Introduction}

Organizations rely on projects as a special kind of temporary organization, spending billions of dollars on them annually, with predictions of even further growth in the global economy (Creasy and Anantatmula 2013). Unlike permanent organizations,

Kai-Kristina Lattrich

Kai-Kristina.Lattrich@hs-ruhrwest.de

1 Institute of Marketing and Management, University of Hohenheim, (570B) Schwerzstr. 42, 70593 Stuttgart, Germany

2 Institute of Civil Engineering, Ruhr West University of Applied Sciences, Duisburgerstr. 100, 45479 Mülheim an der Ruhr, Germany 
temporary organizations (TOs) involve "a temporally bounded group of interdependent organizational actors, formed to complete a complex task" (Burke and Morley 2016, p. 3); when they are established in the form of projects, they seek to achieve a complex, limited, unique product, service, or outcome. With this goal, these organizational forms often integrate diverse, specialized intellectual resources and expertise (Sydow et al. 2016). To arrive at viable solutions, project members must interact continually to perform highly interconnected tasks (Goodman and Goodman 1976).

In practice though, project work also tends to involve team members with different home bases; so, a recurring dilemma arises, between participants' own autonomy requirements and their embeddedness in organizational settings (Burke and Morley 2016; Sydow et al. 2016). In many cases, this dilemma "is a persisting cause of tension and conflict" (Grabher 2010, p. 208) that can encompass ambiguous hierarchies and changing work teams (Tyssen et al. 2013) and thereby determine the project leaders' working conditions too. That is, project leaders must deal with distinct interaction problems, as well as ensure continual interrelations among the team, in TOs. To suggest ways to do so, some studies highlight the importance of effective leadership for achieving preferred project team performance and project results (Poel et al. 2014; Thamhain 2009) or cite poor leadership as a reason for failures (Bohinc 2011). However, we still suffer limited understanding of the influence of leaders' own working conditions on their project management, including the potential links among the project leaders' relevant resources, wellbeing, and project outcomes. This omission is surprising, since project leaders' working conditions could be essential to project goal attainment and therewith project success.

To capture project leaders' working conditions, related to their uncertain but necessary access to the entire team, we draw on the job demands-resources (JD-R) model as a theoretical framework. This model is well established in psychology and human resources literature, used to assess the relationships of working conditions with outcomes in various occupations. According to Hakanen et al. (2008), an essential assumption of the JD-R model is that, regardless of the type of job, psychosocial work characteristics can be categorized into either job resources or job demands (Demerouti et al. 2001; Schaufeli and Bakker 2004). General predictions about the main effects of job demands and resources on strain and motivation have been widely confirmed in permanent organization contexts (Bakker and Demerouti 2014; Taris and Schaufeli 2015) but not yet in relation to TOs. We anticipate that the JD-R model applies to TOs though, because working in TOs can affect motivation (e.g., clear, reachable, tangible goals) and stress (e.g., lost resources, changed, preferences or priorities) (Gällstedt 2003). To apply the model to a project context, we include role overload as a well-established, context-relevant demand. For the resources, we propose an extension of the conventional JD-R model, because previously identified resources do not fit well with project management contexts and characteristics. Therefore, we introduce two new project leaderspecific, team-dependent resources that are particularly relevant for project management and TO contexts: information control and team control. Both forms are fundamental for steering a project, but they are not ensured resources of project 
leaders (Gemünden et al. 2018; Sydow et al. 2016; Goodman and Goodman 1976; Grabher 2010; Aaltonen and Kujala 2010). They also reflect the project leaders' dependence on team cooperation. With this model specification, we pose a central question: To what extent do role overload and information and team control influence project leaders' well-being and, thus, project outcomes?

To answer this research question in detail, we had to consider controversies regarding whether the matching principle of demands and resources (reflecting qualitatively identical dimensions) is relevant (Jonge et al. 2010; Häusser et al. 2010) and the extent to which their influences might be ambivalent (see Widmer et al. 2012; Webster et al. 2011), as well as whether moderators in stress and motivation processes can be generalized (Bakker et al. 2005, 2007; Schaufeli and Taris 2014). Thus, we examine the effects of the newly proposed resources, information and team control, on positive experience as a special kind of well-being (motivational process), as well as the effect of role overload on negative experiences (stress process). Then, we include the effects of both types of experiences on project goal attainment, as an ultimate organizational outcome. Moreover, we investigate the interaction effects of demands and resources across motivational and stress processes.

In doing so, we make four main contributions. First, we extend the JD-R model to include project leader- and TO-specific working conditions, by identifying two important but hitherto neglected drivers of project success and project leader wellbeing, in the form of information and team control. Second, we show that these resources each represent elements of a different set of motivation factors, which helps to extend the applicability of the model to novel research areas. Third, we investigate and confirm a direct effect of team control (resource) on project goal attainment, which challenges a widespread tendency to focus exclusively on mediated effects in the JD-R model. Fourth, our interaction analyses provide insights into the resource-dependent ambivalence of role overload, suggesting the need to reconsider a priori declarations of stressors and use simple slope analyses to assess ambivalent effects. This new perspective on role overload indicates it is a challenge stressor with ambivalent effects, not just a hindrance stressor. The implications of these findings offer guidance for handling high role overload and improving project leaders' working conditions, both of which can benefit project goal attainment outcomes.

\section{Theoretical framework}

\subsection{Project leader-specific working conditions}

To match the project context, we expand the set of well-established resources in prior JD-R research to include more project leader-specific requirements and thereby build our research model (see Fig. 1). Project leaders can create working conditions, such as the often-investigated resource job autonomy, on their own; so, we do not investigate the influence of job autonomy. Rather, team-dependent control is not guaranteed, but without the assurance of such resources, successful 


\section{Resource / Demand Well-being Organizational Outcome Motivation / Stress}

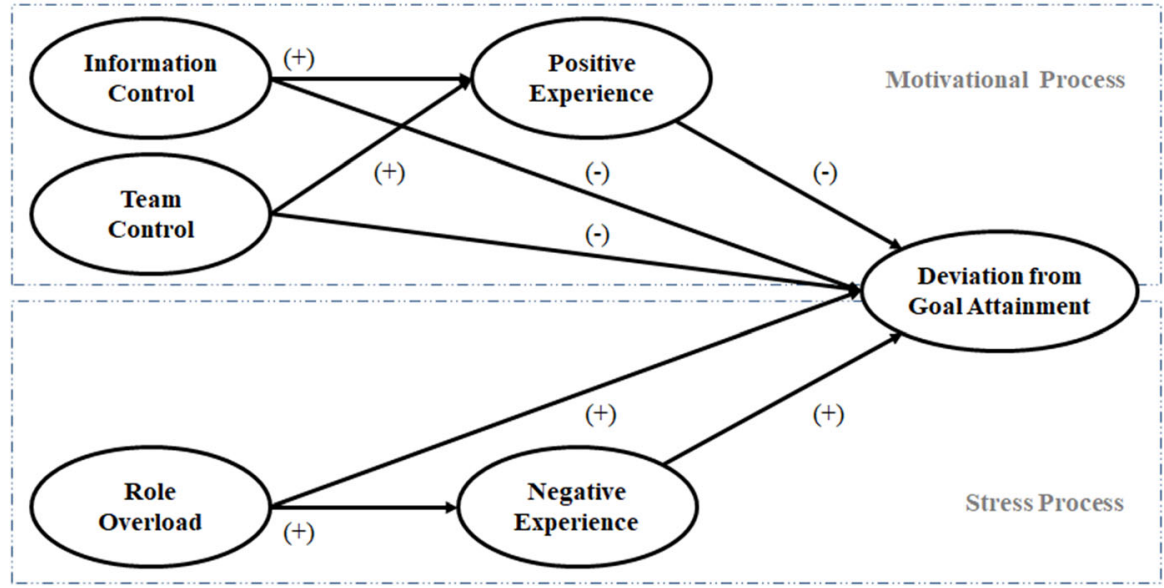

Fig. 1 Conceptual Model

project management is far more difficult to achieve. Therefore, we introduce information and team control in a first step.

First, information control arises when "high information quality helps to allocate resources better according to value creation, risk and strategic goals, and it speeds up decision-making processes" (Gemuenden et al. 2018, p. 6). In a project though, there is usually little time "to build communal knowledge during the lifetime" (Sydow et al. 2016, p. 1480). Therefore, project leaders' information control is a fundamental but not guaranteed characteristic. We also propose a more detailed definition of information control, as project leaders' perceived control over access to information during the project's duration, which provides them with a basis for initiating appropriate actions. When it is high, project leaders enjoy good opportunities to steer the project.

Second, team control is relevant, because temporary, often interorganizational teams embrace different objectives, goals, and team strategies; so conflicts of interest are likely (Grabher 2010; Aaltonen and Kujala 2010; Sydow et al. 2016). Project leaders often struggle to attain team control, despite its important effects on their ability to fulfill their tasks and responsibilities. For this study, we define team control as project leaders' perceived control over the team's activities during the project, which builds on a definition of job control as "the working individual's potential control over ... tasks and ... conduct during the working day" (Karasek 1979 , p. 289), with a more leader- and project-specific approach.

Third, in line with prior research that explains poor leadership (particularly in project management contexts) by citing excessive workloads (e.g. Haynes and Love 2004), we include role overload as a project leader-specific demand. It reflects the degree to which project leaders have "too much work to do in the time available" (Beehr et al. 1979, p. 42). 


\subsection{Project leader well-being and goal attainment}

The most researched dependent variables in the JD-R model are different kinds of individual well-being and strain, such as engagement, disengagement, or burnout. Moreover, extant research has established how job demands and resources influence organizational outcome variables such as withdrawal, organizational commitment, connectedness, absenteeism, turnover intentions, and performance (Bakker et al. 2004, 2008b). We further investigate demands' and resources' influences on project leaders' well-being during the project and on project goal attainment.

Project experience. As a new kind of well-being at work, the project experience reflects an appraisal of the overall working situation. Using the definition of workrelated subjective well-being (SWB) by Diener et al. (2009), we assert that an employee has high work-related SWB if he or she is satisfied with the job and experiences frequent positive and infrequent negative emotions. Bakker and Oerlemans (2012) add work engagement (i.e., vigor, dedication, and absorption), happiness, and job satisfaction as forms of work-related SWB. We therefore define the project experience as positive if the project leader is dedicated and satisfied with the project work; job satisfaction indicates positive affective experiences for employees (Schleicher et al. 2004), and dedication implies a significant and meaningful pursuit (Bakker et al. 2008a). According to the widely accepted definition of "frustration" as a reaction to unfulfilled needs or unresolved problems (see, e.g., Matsumoto 2009), we instead define the appraisal of the overall project as a negative experience if a leader confronts frustrating or unsatisfactory situations during the project duration.

Goal attainment. Deviation from goal attainment is a crucial project outcome. Reflecting our particular research focus on the influence of project leaders' working conditions on project goal attainment, the conceptual model includes negative goal deviation as a measurement unit for organizational outcomes. Goal attainment typically indicates project success (e.g., Flyvbjerg 2014), according to cost, timeline, and quality criteria. Deviation from such goal attainment reflects any divergence from these initial targets, corresponding to the definition of "performance" by Roe et al.(1999), as congruence between targets and process results. To this extent, goal deviation is the final result of the project task fulfillment and interaction of all project members and stakeholders.

\subsection{Hypotheses development}

In accordance with the basic idea of the JD-R model, which combines the motivational process of using resources and the stress process of facing demands, we investigate the influence of job resources and job demands on well-being and organizational outcomes initially by studying motivational and stress processes separately. We predict moderating effects of both resources and demands, while noting the controversial discussions about evidence of buffering effects of job resources on demand consequences or the active job effect of demands on the relation of job resources with well-being (Bakker et al. 2005, 2007; Xanthopoulou et al. 2007; Hakanen et al. 2005; Karasek 1979; Schaufeli and Taris 2014). 


\subsection{Motivational process}

The motivational process in the JD-R model describes how job resources trigger employees' motivation and result in increased positive outcomes such as commitment or positive attitudes toward work (Hakanen et al. 2008). Studies have established that resource control facilitates positive work experiences, intrinsic motivation, and states of psycho-physical well-being (Weigl et al. 2010). For the present study, we anticipate that the two control constructs increase positive experiences, which should reduce deviations from goal attainment. In accordance with the JD-R model, for the motivational process, we predict:

H1 More positive experiences partially mediate the decreasing effects of (a) information control and (b) team control on deviation from goal attainment

\subsection{Stress process}

To describe the stress process, the JD-R model draws attention to positive associations between job demands and disengagement, burnout, and poor performance (see, e.g. Glaser et al. 1999; Hakanen et al. 2008). We, thus, anticipate that role overload enhances negative experiences, which in turn increases deviation from goal attainment. Thus, for the stress process, we propose:

$\mathrm{H} 2$ More negative experiences partially mediate the increasing effect of role overload on deviation from goal attainment

\subsection{Moderating effects}

Stress process. Resources can "buffer" the influence of demands on stress (e.g., Bakker et al. 2005), though this buffering effect might depend on whether demands and control reflect qualitatively identical dimensions, such as psychological demands and resources versus physiological versions (i.e., matching principle) (Häusser et al. 2010). We argue that leader-specific resources may be of particularly great importance for project leaders who need to overcome role overload to complete their project goals. The control constructs should buffer the influence of role overload on negative experiences and thus the deviation of goal attainment. Formally, we hypothesize:

H3 (a) Information control and (b) team control buffer the impact of role overload on negative experiences, such that the relationship is stronger for project leaders with lower information and team control than for those with higher information and team control

$\mathrm{H} 4$ (a) Information control and (b) team control buffer the impact of role overload on deviations from goal attainment, such that the relationship is stronger for project leaders with lower information and team control than for those with higher information and team control 
Motivation process. To the best of our knowledge, few studies cite any moderating effects of demands. Bakker and Sanz-Vergel (2013) identify a moderating effect of high emotional demands on the relationship between personal resources and work engagement that can be reversed. According to Karasek's (1979) hypothesis about "active jobs," work engagement is greatest when people have both high personal resources and high emotional demands; in cases marked by low personal resources and high emotional demands, work engagement instead is lowest. Once demands exceed employees' adaptive capacities, they can turn into stressors and elicit burnout. This discussion raises questions about the a priori definition of stressors, as challenge or hindrance forms ((Webster et al. 2011; Widmer et al. 2012). Studies that adopt a challenge-hindrance framework suggest the potential ambivalence of job demands (Webster et al. 2011; Widmer et al. 2012), but such ambivalence has not been addressed in relation to the JD-R model, despite its clear relevance for a model that combines motivational and stress processes. Furthermore, extant research calls for efforts to consider job demands as challenge and hindrance stressors (Demerouti and Bakker 2011). With the prediction that role overload is predominantly a challenge stressor that has ambivalent effects, we expect that high levels combined with high control increase positive experiences and also decrease deviations from goal attainment. However, high role overload and low control should reduce positive experiences while increasing negative goal deviation. We predict:

H5 Role overload moderates the positive relationship of (a) information control and (b) team control with positive experiences, such that the relationship is stronger for leaders with higher role overload

H6 Role overload moderates the negative relationship of (a) information control and (b) team control with deviation from goal attainment, such that the relationship is stronger for leaders with higher role overload

\section{Materials and methods}

To test our hypotheses, we use structural equation modeling. After developing the questionnaire, we consulted with experienced project managers and methods experts to discuss any potential difficulties in understanding. To generate the necessary data set, we contacted a German project management organization (GPM) to request access to its 7000 members, and then posted invitations to participate on its homepage and in a newsletter. The GPM published a short project description and link to the online survey. We also sent the survey links to project leaders in Germany, identified through personal contacts or search results on platforms like LinkedIn and Xing. Due to our focus on project leaders on the customer side, relatively few members of the GPM fit all the criteria, but they represent the actors who likely have the strongest individual influences on project outcomes and efforts to attain project goals. These project-responsible managers include project leaders, subproject leaders, executive directors, or professional experts on the customer side. 
We asked participants to answer the survey in reference to the latest project they had completed.

The invitations prompted 1527 site views. We created 443 data sets, and 222 participants completed the survey. Thus, the completion rate is around $14.5 \%$. Considering our limitations of accessing project-responsible leaders on the customer side only, we regard the participation rate as acceptable.

\subsection{Sample}

The final sample consists of project leaders from several organizations in different industries (e.g., IT, finance, pharmaceuticals, engineering, automotive, infrastructure, services, consumer goods, research). After excluding participants with incomplete data, the final sample consists of 185 German-speaking project leaders ( $80 \%$ men, 20\% women), ranging in age from 24 to 72 years (average of 44 years). Their work experience mostly exceeds 10 years $(67.2 \%), 16.76 \%$ have 5-9 years' work experience, and $14.05 \%$ have less than 5 years' experience. Furthermore, these project leaders indicate an average of 13 years of project experience. We consider the number of employees in the organization to reflect the organizational context. The average was 206 employees, though the greatest proportion involved large companies with more than 1,000 employees $(60.54 \%)$. Thus, the results are especially relevant for projects undertaken by big companies. As a measure of project complexity, we asked about project duration (mean $=35$ months), volume $(20,000 €$ to $5,100,000 €)$, and the number of project groups with different interests (which reached projects with more than 40 parties). These characteristics indicate the sample is heterogeneous, spanning less complex to major projects.

\subsection{Measures}

We developed a questionnaire with established measures, and then checked the content validity of the newly developed or adjusted items by asking for input from an expert panel of project management professionals. Following Chang et al. (2010), we designed the questionnaire to reduce the risk of common method variance (CMV), such that we ensured the anonymity of the responses and separated measures of the predictor and criterion variables in the survey instrument. In addition, we used different scale endpoints and formats for the predictor and criterion measures (Podsakoff et al. 2003). All the exogenous variables used Likerttype scales, but one endogenous scale was a metric scale. The inclusion of these measures into a comprehensive questionnaire, with overlapping study interests, meant it would have been difficult for respondents to cognitively "create" the correlations necessary to produce a CMV-biased pattern of responses (Chang et al. 2010).

Information control. We measured information control with a self-developed, four-item scale based on the traditional "magic triangle" of project management, entailing quality, time, and cost (Kerzner 2013). The current status toward goal attainment, as measured by costs, timelines, quality targets, and project deficits (invoking the often-contested nature of information; (Bruijn and Leijten 2007) is 
crucial for decision-making in project management and provides the framework for action. Project leaders' responses to questions about costs, timelines, quality targets, and project deficits, thus, reflect the status of their information control (e.g., "I was aware of the status of the costs"; "I was aware of the project's deficits"). The respondents indicated their agreement with the items on seven-point Likert-type scales ranging from 1 (never) to 7 (always).

Team control. We measured team control with a four-item scale, based on the perceived control of time scale by Claessens et al. (2004), adapted to a project planning context. Items included, "The team members kept to their agreements" and "The execution of the tasks went according to my expectations." Respondents indicated their agreement with the items on seven-point Likert-type scales ranging from 1 (never) to 7 (always).

Role overload. We used a four-item scale adapted from Brown et al. (2005), in which the items are consistent with Beehr et al.'s (1979) conceptual definition of role overload. For example, we asked participants, "How often did you feel that you were unable to complete all of the tasks at the same time?" and "How often did you feel overloaded?" The responses appeared on seven-point Likert-type scales ranging from 1 (never) to 7 (always).

Experiences. We measured project leaders' experience with two separate constructs: positive and negative. For positive experiences, we used a four-item scale adopted from Schaufeli (2006), pertaining to dedication, and from Spector (1997), pertaining to work satisfaction, including: "Working on the project was exciting in a positive way" and "Working on the project was a positive challenge for me." Then we assessed negative experiences with a four-item scale derived from the frustration scale by Peters et al. (1980), including: "Working on the project was a very frustrating experience" and "Being unhappy comes with the project work." The respondents indicated their agreement with these items on seven-point Likerttype scales ranging from 1 (never) to 7 (always).

Deviation from goal attainment. To measure project goal attainment, we asked the participants to specify their goal deviation in terms of time, cost, and quality (Lavagnon 2009). Similar to Creusen and Schoormans (2005), we divided quality into functional or esthetic (e.g., design, graphics, haptics). We also asked about any adjustment of project goals at the end of the project, in reference to the goals at the time of the initial cost estimation, which represents a common milestone in project settings. We used negative goal deviation exclusively, to reduce complexity; positive goal deviation is extremely unusual in a project management context. The direction of causality in the measurement model runs from the measure to the construct, and dropping an indicator would have altered the meaning of the construct, so deviation from goal attainment is a formative measure (Jarvis et al. 2003). The item asked participants to "Please enter the deviation of goal attainment at the end of the project." They provided percentages of deviation for the cost, time, functional quality, and esthetic quality, using a continuous ratio scale that indicates whether the project was more expensive, longer, or worse in quality than planned. 


\subsection{Analysis}

For the data analysis, we employed partial least squares path modeling (PLS-PM), which is an ordinary least squares regression-based method of structural equation modeling. For this study, PLS-PM is appropriate, for three main reasons. First, the model includes reflective and formative measures with continuous scales. Second, the sample size of 185 is adequate, according to Chin's (1998) recommendation that the sample size should be greater than ten times the largest number of indicators for a latent factor or the largest number of predictors for a latent outcome. Third, the model is complex and includes interaction effects.

\section{Results}

Self-reported data collected at the same time can create common method biases, such as consistency motifs or social desirability concerns (Podsakoff et al. 2003). To test for common method bias, we use Harman's one-factor test (Podsakoff and Organ 1986), which suggests no notable bias for our data, at $44 \%$. We also adopt the marker variable technique (Williams et al. 2010), in accordance with the guidelines proposed by Rönkkö and Ylitalo (2011) for PLS-PM. When we include a marker variable as an additional latent variable in the model and analyze its impact, the results show that the significance of the various paths does not change between the baseline model and adjusted model. Thus, CMV does not appear to bias our findings. Finally, when we include the project complexity characteristics in our model, we find significant correlations only between project volume and team control $(\beta=-0.228, p<0.01)$ and information control $(\beta=-0.213, p<0.01)$. This result aligns with our project definition and project leader challenges, which should be more substantial for larger projects. Thus, we find no disturbing influences of project characteristics in the data set.

\subsection{Reflective measurement model}

The outer loadings of each item in Table 1 reveal that they are all clearly greater than the desired minimum of 0.70 (Fornell and Larcker 1981b).

In Table 2, the composite scale reliabilities are all greater than the 0.70 cutoff value too (Nunnally and Bernstein 1994), and the Cronbach's alpha value further suggests internal consistency. In support of convergent validity, we identify satisfactory average variance extracted values, greater than 0.72 (Chin 1998). These values also offer evidence of discriminant validity according to the Fornell-Larcker criterion (Fornell and Larcker 1981a).

\subsection{Formative measurement model}

The results in Table 3 show that all of the variance inflation factors (VIF) are above 0.2 and less than 5 (Hair et al. 2011). Thus, multicollinearity should not pose a problem. Similar to Henseler et al. (2009), we conducted significance tests for all 
Table 1 Outer loadings for item reliability

\begin{tabular}{lrrrrr}
\hline & \multicolumn{1}{c}{ ICon } & \multicolumn{1}{c}{ PosEx } & \multicolumn{1}{c}{ NegEx } & \multicolumn{1}{l}{ TCon } & \multicolumn{1}{c}{ ROve } \\
\hline ICon_01 & $\mathbf{0 . 8 0 1}$ & 0.540 & -0.502 & 0.574 & -0.229 \\
ICon_02 & $\mathbf{0 . 8 9 3}$ & 0.489 & -0.534 & 0.594 & -0.248 \\
ICon_03 & $\mathbf{0 . 8 5 4}$ & 0.486 & -0.510 & 0.493 & -0.328 \\
ICon_04 & $\mathbf{0 . 8 4 0}$ & 0.382 & -0.447 & 0.402 & -0.316 \\
PosEx _01 & 0.551 & $\mathbf{0 . 9 0 2}$ & -0.647 & 0.629 & -0.195 \\
PosEx _02 & 0.547 & $\mathbf{0 . 9 2 0}$ & -0.695 & 0.601 & -0.270 \\
PosEx_03 & 0.558 & $\mathbf{0 . 9 2 0}$ & -0.698 & 0.587 & -0.240 \\
PosEx_04 & 0.587 & $\mathbf{0 . 9 1 5}$ & -0.705 & 0.621 & -0.318 \\
NegEx_01 & -0.550 & -0.698 & $\mathbf{0 . 8 9 4}$ & -0.547 & 0.434 \\
NegEx_02 & -0.526 & -0.630 & $\mathbf{0 . 8 9 5}$ & -0.484 & 0.391 \\
NegEx_03 & -0.573 & -0.598 & $\mathbf{0 . 8 7 6}$ & -0.527 & 0.454 \\
NegEx_04 & -0.616 & -0.760 & $\mathbf{0 . 9 2 6}$ & -0.605 & 0.466 \\
TCon_01 & 0.605 & 0.586 & -0.532 & $\mathbf{0 . 8 9 5}$ & -0.364 \\
TCon_02 & 0.631 & 0.611 & -0.580 & $\mathbf{0 . 8 7 4}$ & -0.297 \\
TCon_03 & 0.554 & 0.590 & -0.505 & $\mathbf{0 . 9 0 1}$ & -0.326 \\
TCon_04 & 0.555 & 0.581 & -0.528 & $\mathbf{0 . 8 8 8}$ & -0.373 \\
ROve_01 & -0.286 & -0.185 & 0.369 & -0.322 & $\mathbf{0 . 9 1 0}$ \\
ROve_02 & -0.311 & -0.260 & 0.460 & -0.354 & $\mathbf{0 . 9 5 1}$ \\
ROve_03 & -0.366 & -0.313 & 0.523 & -0.381 & $\mathbf{0 . 9 0 6}$ \\
ROve_04 & -0.293 & -0.249 & 0.408 & -0.332 & $\mathbf{0 . 8 9 6}$ \\
\hline Bord & & & &
\end{tabular}

Bold indicates Conceptual Model

the paths in the model. Although not all of the indicators achieve significant weight (see Table 3), we include them in the subsequent (structural) analyses, because their outer loadings are greater than 0.5 and significant (Hair et al. 2011).

\subsection{Structural model}

We assessed the structural model to determine how well the empirical data fit the proposed model, with a VIF index to test for multicollinearity. The VIF of each independent variable ranged from 1.45 to 2.95 , well below the typical threshold value of 10 (MacCallum and Browne 1993). Figure 2 presents the results of the PLS-PM algorithm and the bootstrapping process (5000 subsamples, individual sign changes). The significance and relevance of the structural model relationships, the coefficient of determination $\left(R^{2}\right.$ value), and the effect sizes $\mathrm{f}^{2}$ also support the proposed model (e.g., Hair et al. 2014). The only model fit index implemented for PLS-PM is the standardized root mean square residual (SRMR), with a cut-off value of 0.08 (Hu and Bentler 1999). Overall, we find evidence of good model fit, because the SRMR reaches 0.044 . 


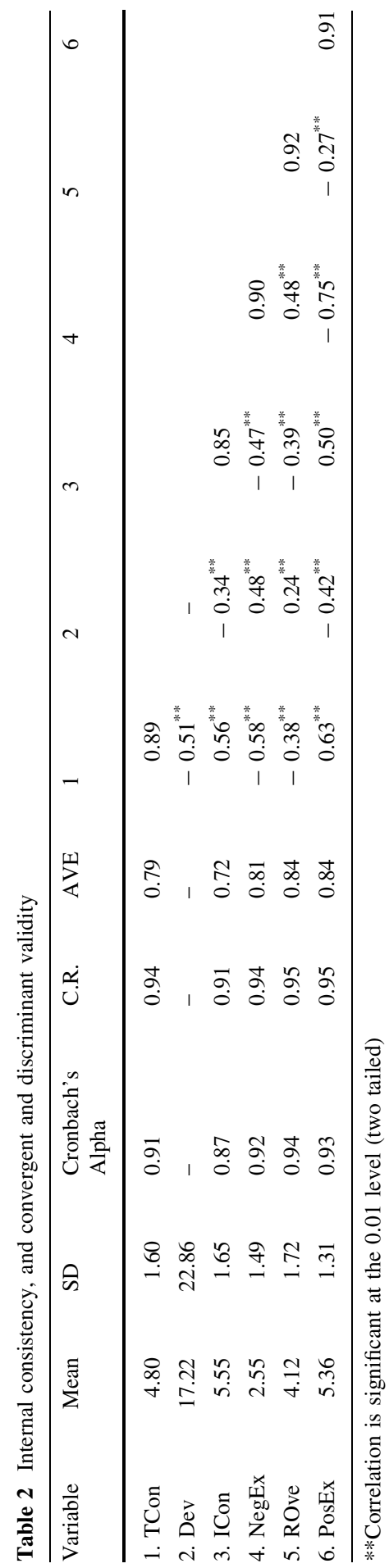


Table 3 Multicollinearity and validity

\begin{tabular}{lllllr}
\hline Variable & Variance inflation factor & Weight & $t$ value & Loading & $t$ value \\
\hline Dev_Costs & 1.635 & 0.227 & 2.470 & 0.716 & 10.364 \\
Dev_Time & 1.576 & 0.595 & 6.754 & 0.832 & 15.759 \\
Dev_Esthetic Quality & 1.948 & 0.107 & 0.911 & 0.511 & 5.080 \\
Dev_Functional Quality & 1.911 & 0.427 & 3.680 & 0.664 & 7.834 \\
\hline
\end{tabular}

$\begin{array}{ll}\text { Resource / Demand } & \text { Well-being } \\ \text { Motivation / Stress } & \text { Organizational Outcome }\end{array}$

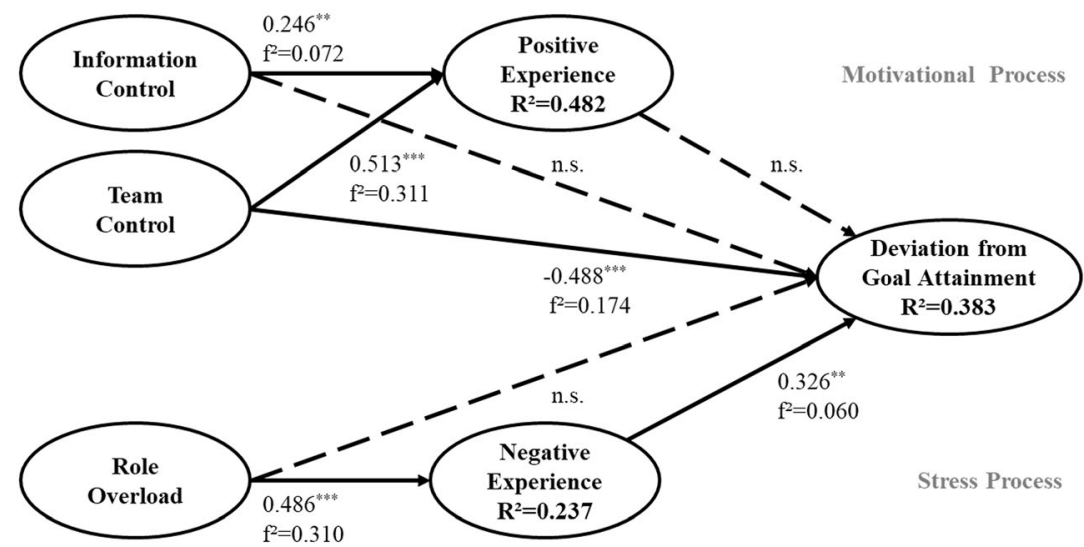

Dotted lines represent non-significant paths. Solid lines represent statistically significant path: ${ }^{* *} p<0.01 ;{ }^{* * *} p<0.001$

Fig. 2 PLS-based path modeling of the influence of team control and role overload on experience appraisal and goal attainment $(N=185)$ around here

\subsection{Path modeling}

In the motivational process, as expected, project leaders' team and information control increase positive experiences $(\beta=0.246, p<0.01$ and $\beta=0.513$, $p<0.001$, respectively). However, we do not find any significant relationship between positive experience and deviation from goal attainment; so, we must reject the assertion that positive experiences partially mediate the decreasing effect of information and team control on deviations from goal attainment (H1a/b). Instead, we find evidence of a direct effect of team control on deviation from goal attainment ( $\beta=-0.488, p<0.001)$; the direct effect of information control on deviation from goal attainment is not significant.

In relation to the stress process, we find evidence of both direct effects $(\beta=0.486, p<0.001$ for role overload on negative experience; $\beta=0.326$, $p<0.01$ for negative experience on deviation from goal attainment). To test the mediation hypothesis, we used a bootstrapping method (Preacher and Kelley 2011). 
The results, in Table 4, support $\mathrm{H} 2$; negative experience fully mediates the influence of role overload on the deviation from goal attainment; whereas, the direct effect of role overload on deviation of goal attainment is not significant.

\subsection{Moderating effects}

In $\mathrm{H} 3-\mathrm{H} 6$, we predicted that role overload and control interact to affect experience appraisals and deviation from goal attainment. To test these moderating effects, we computed standardized cross-product interaction constructs (orthogonal method) and included them in the equations (Henseler and Chin 2010). The PLS-PM analysis reveals just three significant effects (and we reject H3b, H4a/b, H5a, and H6a). The confidence intervals (CIs) of the significant interactions do not include 0 , in additional support of these findings. We plot the interactions using simple slope analyses, as detailed in Figs. 3, 4 and 5. First, Fig. 3 reveals the buffering effect of information control on the stress process between role overload and negative experience $(\beta=-0.140, p<0.01,95 \%$ CI $[-0.260,-0.078])$. The positive effect of role overload on negative experience is stronger among project leaders with lower information control than among those with higher information control, in support of H5b. Second, Fig. 4 depicts the moderating effect of role overload on the motivational process involving team control and positive experience $(\beta=0.191$, $p<0.01,95 \%$ CI $[0.073,0.248])$. The positive effect of team control on positive experience is strongest for project leaders with more role overload, as we predicted in H3a. Third, the moderating effect in Fig. 5 involves role overload in the motivational process between team control and deviation from goal attainment $(\beta=-0.127, p<0.1,95 \%$ CI $[-0.281,-0.050])$. In support of H6b, the negative effect of team control on deviation from goal attainment is strongest for project leaders with more role overload.

\section{Discussion}

Project leaders' overall task of "leading to the goal" can be particularly difficult, due to "typically uncertain, complex and unique" tasks (Burke and Morley 2016, p.8). We not only apply a JD-R model but also expand it, by introducing project leaders' performance-relevant working conditions (role overload, team and information control) and examining how these demands and resources affect well-being (project experience appraisal) and project goal attainment. Thus, this

Table 4 Bootstrapping confidence intervals and kappa square statistics

\begin{tabular}{|c|c|c|c|}
\hline & \multicolumn{3}{|c|}{ Negative experience } \\
\hline & \multicolumn{3}{|c|}{ Bootstrapping (95\%) CI } \\
\hline & Lower limit & Upper limit & $\kappa^{2}$ \\
\hline Role overload $\rightarrow$ Deviation from goal attainment & 1.6518 & 3.5692 & 0.2107 \\
\hline
\end{tabular}




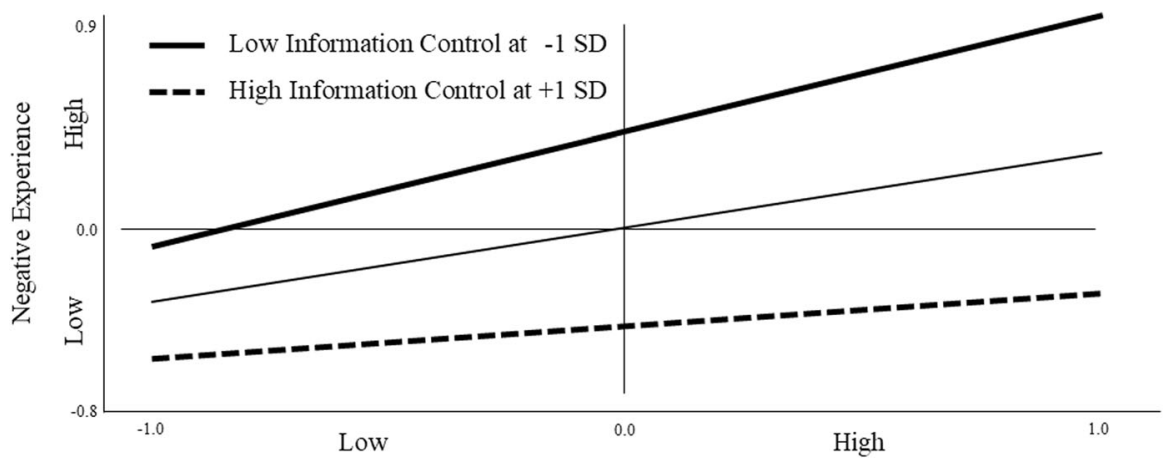

Role Overload

Fig. 3 Moderating effect of information control on the relationship of role overload and negative experience around here

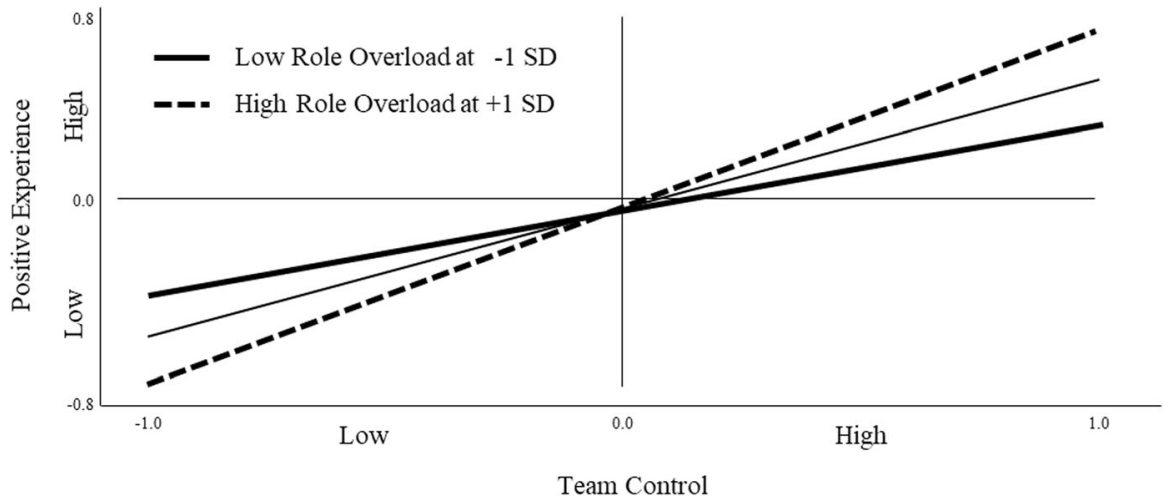

Fig. 4 Moderating effect of role overload on the relationship of team control and positive experience around here

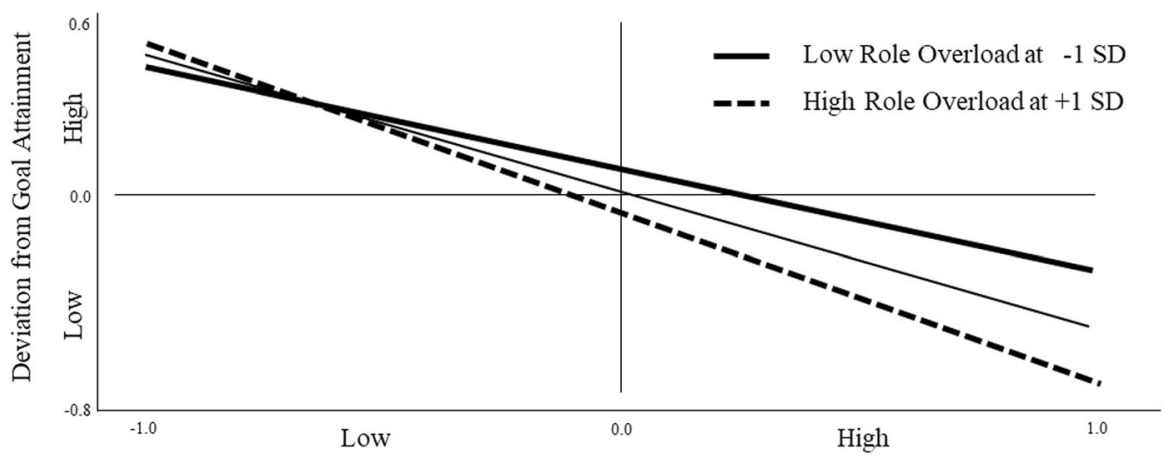

Team Control

Fig. 5 Moderating effect of role overload on the relationship of team control and deviation from goal attainment around here 
study contributes to extant literature on JD-R research, TOs, and project management in several ways.

First, the newly developed team-dependent constructs, information control and team control, strongly affect experience appraisals and goal attainment. The results confirm the relevance of both control constructs for project leaders. Information control emerges as a critical resource (Gemuenden et al. 2018). Team control is not always guaranteed, and conflicts can influence interrelations among team members (Grabher 2010). We expand previous research by accounting for these project leader-specific and team-dependent resources for the first time.

Second, the distinct effects of the two control constructs are notable, insofar that some of the non-significant interaction effects may arise due to their varying relevance for project leaders, suggesting a further development of the matching principle (Häusser et al. 2010). Information control seems to be a basic requirement for managing day-to-day work and mastering role overload. However, it is less relevant to the motivational process than team control is. In contrast, team control represents a performance requirement that, in combination with high role overload, leads to the best performance (in line with the notion of different sets of motivation factors; Herzberg et al. 1993). The results expand the JD-R model by indicating ways it can be useful in determining additional resource classifications and, thus, creating a new application area.

Third, the mediation analyses indicate full mediation for the stress process with negative experience as a mediator, but they reveal non-mediation for the motivation process, such that information and team control have only direct effects on deviation from goal attainment. These results inform JD-R research by calling into question a common assumption of mediated effects, without any explicit analysis (Taris and Schaufeli 2015; Bakker and Demerouti 2007).

Fourth, former research has indicated the relatively low relevance of interaction effects within the JD-R model (Taris and Schaufeli 2015; van der Doef and Maes 1999); we also note previous calls to integrate challenge and hindrance stressors in JD-R models (Demerouti and Bakker 2011; Taris and Schaufeli 2015). In this sense, perhaps, the most important contribution of this study is its demonstration of the ambivalent effects of role overload, according to our detailed moderation analyses. Information control acts as a buffer in the stress process between role overload and negative experiences, and in turn, we can presume that the negative effect of role overload depends on information control. We also find moderating effects of role overload on the relationship between team control and positive experiences and on the effect of team control on deviation from goal attainment. That is, the results indicate that high role overload leads to both the most and the least positive experiences, as well as the lowest and highest deviation from goal attainment. However, role overload only has a negative influence on goal attainment and positive experience in combination with low team control. These results align with the notion of an "active job" (Karasek 1979). The moderation analyses also indicate that it may be most appropriate to classify role overload as a predominant challenge stressor, with an ambivalent nature, such that its negative effect arises only in combination with low information or team control. This finding itself features three novel insights: The ambivalent effect challenges a conventional, a 
priori separation of challenge and hindrance stressors (e.g., challenge-hindrance stressor framework; Boswell et al. 2004; (Cavanaugh et al. 2000; Boswell et al. 2004; LePine et al. 2004; Pearsall et al. 2009; Crawford et al. 2010; Searle and Auton 2015), such that it appears advisable to identify the predominant effect of a stressor while also checking for its potentially ambivalent nature (Widmer et al. 2012; Webster et al. 2011). The JD-R model in combination with simple slope analyses can assess such ambivalent effects. Finally, this result offers a new perspective on role overload. To date, prior research has classified it as a hindrance demand (Crawford et al. 2010; LePine et al. 2005); our results expand such views by proposing a new classification of role overload.

\subsection{Limitations and further research}

This study includes several limitations. First, we sampled data from various companies in diverse industries. This approach limits our ability to control for contextual factors. However, sampling a variety of companies and industries can be considered a benefit, in that it increases the generalizability of the findings across various settings. Second, the collected data come from project leaders, as a specific type of executive. Continued studies might confirm the generalizability of this study's results, especially with regard to the ambivalence of role overload, for executives working in other contexts. Third, a longitudinal study design could provide further insights into the proposed effects in our research model. The effects of role overload, especially, might differ over time; the positive influences on project leaders' well-being even could become negative if overload persists across time and multiple projects. Fourth, further research should include a second, independent estimation of goal attainment to decrease any remaining risk of common method bias. Fifth, in light of the results, it may be fruitful to research antecedents that influence leaders' demands and resources in both JD-R and leadership research contexts.

\subsection{Practical implications}

The study results have important implications for organizational practice. First, organizations should strengthen their project leaders' team control. The buffering effect of information control suggests that, to avoid or at least decrease negative experiences (and increase goal attainment), organizations should strengthen their project leaders' information control. In addition, the findings reveal that, in a project context, role overload is a challenge demand that interacts with control, which also underlines the importance of strengthening control. Moreover, due to the risk that role overload's influence can shift from positive to negative, it may be more effective for organizations to try to influence control than role overload; the former has a strong influence, but the latter might be difficult to avoid.

Second, to improve their project goal attainment, organizations should ensure their leaders have sufficient resources. This point is not to say that enhancing resources should be the only objective, but a primary aim should be to allow project 
leaders to design project teams in ways that minimize conflicts of interest. Then, the selected team can support their leader without restriction.

Third, interventions at the organizational level can help to detect problems during the project duration. A pertinent method would be to create quality gates (see StageGate System: Cooper 1990) to ensure organizations analyze and confirm the achievement of quality goals, with consideration of leaders' needed resources, demands, and well-being. Especially when the situation involves low control and negative experiences, organizations should assist project leaders by discussing the circumstances and searching for ways to improve their control.

Open Access This article is licensed under a Creative Commons Attribution 4.0 International License, which permits use, sharing, adaptation, distribution and reproduction in any medium or format, as long as you give appropriate credit to the original author(s) and the source, provide a link to the Creative Commons licence, and indicate if changes were made. The images or other third party material in this article are included in the article's Creative Commons licence, unless indicated otherwise in a credit line to the material. If material is not included in the article's Creative Commons licence and your intended use is not permitted by statutory regulation or exceeds the permitted use, you will need to obtain permission directly from the copyright holder. To view a copy of this licence, visit http:// creativecommons.org/licenses/by/4.0/.

\section{Appendix: Survey Questions}

\section{Information Control}

I knew about the status of the costs.

I knew about the timeline status.

I knew about the realized quality.

I was aware of the project deficits.

Team Control

The execution of tasks went according to my expectations.

The team members kept to their agreements.

I was able to steer the project developments completely.

I was able to determine the project developments.

Role Overload

How often did you feel that you were unable to fulfill all tasks at the same time?

How often did you feel that the workload was unmanageable?

How often did you feel that you were unable to meet the task requirements?

How often did you experience overload?

Positive Experience

Working on the project was exciting in a positive way.

I looked forward to the project work.

Working on the project was a positive challenge for me.

I experienced the project work as positive stress.

Negative Experience

Working on the project was a very frustrating experience.

I found it difficult to motivate myself for the project work.

Being unhappy comes with the project work.

I experienced the project work as negative stress. 


\section{References}

Aaltonen, Kirsi, and Jaakko Kujala. 2010. A project lifecycle perspective on stakeholder influence strategies in global projects. Scandinavian Journal of Management 26 (4): 381-397. https://doi.org/ 10.1016/j.scaman.2010.09.001.

Bakker, Arnold B., and Evangelia Demerouti. 2007. The Job Demands-Resources model: state of the art. Journal of Managerial Psychology 22 (3): 309-328. https://doi.org/10.1108/02683940710733115.

Bakker, A. B., and E. Demerouti. 2014. Job Demands-Resources Theory. In Wellbeing, ed. Cary L. Cooper, Volume 3, 37-64. Chichester et al.: John Wiley \& Sons, Ltd.

Bakker, Arnold B., and Wido G.M. Oerlemans. 2012. Subjective Well-being in Organizations. In The Oxford Handbook of Positive Organizational Scholarship, eds. Gretchen M. Spreitzer, Kim S. Cameron, 178-198. Oxford University Press.

Bakker, Arnold B., and Ana I. Sanz-Vergel. 2013. Weekly work engagement and flourishing: The role of hindrance and challenge job demands. Journal of Vocational Behavior 83 (3): 397-409. https://doi. org/10.1016/j.jvb.2013.06.008.

Bakker, Arnold B., Evangelia Demerouti, and Willem Verbeke. 2004. Using the job demands-resources model to predict burnout and performance. Human Resource Management 3 (1): 83-104. https://doi. org/10.1002/hrm.20004.

Bakker, Arnold B., Evangelia Demerouti, and Martin C. Euwema. 2005. Job resources buffer the impact of job demands on burnout. Journal of Occupational Health Psychology 10 (2): 170-180. https:// doi.org/10.1037/1076-8998.10.2.170.

Bakker, Arnold B., Jari J. Hakanen, Evangelia Demerouti, and Despoina Xanthopoulou. 2007. Job resources boost work engagement, particularly when job demands are high. Journal of Educational Psychology 99 (2): 274-284. https://doi.org/10.1037/0022-0663.99.2.274.

Bakker, Arnold B., Hetty van Emmerik, and Pim van Riet. 2008b. How job demands, resources, and burnout predict objective performance: A constructive replication. Anxiety Stress and Coping 21 (3): 309-324. https://doi.org/10.1080/10615800801958637.

Bakker, Arnold B., Wilmar B. Schaufeli, Michael P. Leiter, and Toon W. Taris. 2008a. Work engagement: An emerging concept in occupational health psychology. Work \& Stress 22 (3): 187-200. https://doi.org/10.1080/02678370802393649.

Beehr, Terry A., Jeffrey T. Walsh, and Thomas D. Taber. 1979. Relationships of stress to individually and organizationally valued states: Higher order needs as a moderator. Journal of Applied Psychology 61: 41-47.

Bohinc, Tomas. 2011. Führung im Projekt: Führungswissen für Projektleiter, 1st ed. Berlin: Springer, Berlin.

Boswell, Wendy R., Julie B. Olson-Buchanan, and Marcie A. LePine. 2004. Relations between stress and work outcomes: The role of felt challenge, job control, and psychological strain. Journal of Vocational Behavior 64 (1): 165-181. https://doi.org/10.1016/S0001-8791(03)00049-6.

Brown, Steven P., Eli Jones, and Thomas W. Leigh. 2005. The attenuating effect of role overload on relationships linking self-efficacy and goal level to work performance. The Journal of applied psychology 90 (5): 972-979. https://doi.org/10.1037/0021-9010.90.5.972.

Burke, Catriona M., and Michael J. Morley. 2016. On temporary organizations: A review, synthesis and research agenda. Human Relations 69 (6): 1235-1258. https://doi.org/10.1177/0018726715610809.

Cavanaugh, Marcie A., Wendy R. Boswell, Mark V. Roehling, and John W. Boudreau. 2000. An empirical examination of self-reported work stress among U.S. managers. Journal of Applied Psychology 85 (1): 65-74. https://doi.org/10.1037//0021-9010.85.1.65.

Chang, Sea-Jin, Arjen van Witteloostuijn, and Lorraine Eden. 2010. From the Editors: Common method variance in international business research. Journal of International Business Studies 41 (2): 178-184. https://doi.org/10.1057/jibs.2009.88.

Chin, Wynne W. 1998. The Partial Least Squares Approach to Structural Equation Modeling. In Modern methods for business research, ed. George A. Marcoulides. Mahwah: Lawrence Erlbaum.

Claessens, Brigitte J.C., Wendelien van Eerde, Christel G. Rutte, and Robert A. Roe. 2004. Planning behavior and perceived control of time at work. Journal of Organizational Behavior 25 (8): 937-950. https://doi.org/10.1002/job.292.

Cooper, Robert G. 1990. Stage-gate systems: A new tool for managing new products. Business Horizons 33 (3): 44-54. https://doi.org/10.1016/0007-6813(90)90040-I. 
Crawford, Eean R., Jeffrey A. LePine, and Bruce L. Rich. 2010. Linking job demands and resources to employee engagement and burnout: a theoretical extension and meta-analytic test. The Journal of applied psychology 95 (5): 834-848. https://doi.org/10.1037/a0019364.

Creasy, Todd, and Vittal S. Anantatmula. 2013. From Every Direction-How Personality Traits and Dimensions of Project Managers Can Conceptually Affect Project Success. Project Management Journal 44 (6): 36-51. https://doi.org/10.1002/pmj.21372.

Creusen, Marielle E.H., and Jan P.L. Schoormans. 2005. The Different Roles of Product Appearance in Consumer Choice*. Journal of Product Innovation Management 22 (1): 63-81. https://doi.org/10. 1111/j.0737-6782.2005.00103.x.

de Bruijn, Hans, and Martijn Leijten. 2007. Megaprojects and Contested Information. Transportation Planning and Technology 30 (1): 49-69. https://doi.org/10.1080/03081060701208050.

de Jonge, Jan, Natasja van Vegchel, Akihito Shimazu, Wilmar Schaufeli, and Christian Dormann. 2010. A longitudinal test of the demand-control model using specific job demands and specific job control. International journal of behavioral medicine 17 (2): 125-133. https://doi.org/10.1007/s12529-0109081-1.

Demerouti, Evangelia, and Arnold B. Bakker. 2011. The Job Demands-Resources model: Challenges for future research. SA Journal of Industrial Psychology 37 (2): 1-9. https://doi.org/10.4102/sajip.v37i2. 974.

Demerouti, Evangelia, Arnold B. Bakker, Friedhelm Nachreiner, and Wilmar B. Schaufeli. 2001. The job demands-resources model of burnout. Journal of Applied Psychology 86 (3): 499-512. https://doi. org/10.1037//0021-9010.86.3.499.

de Poel, F.M., J.I. Stoker, and K.I. van der Zee. 2014. Leadership and Organizational Tenure Diversity as Determinants of Project Team Effectiveness. Group \& Organization Management 39 (5): 532-560. https://doi.org/10.1177/1059601114550711.

Diener, Ed, Ed Sandvik, and William Pavot. 2009. Happiness is the Frequency, Not the Intensity, of Positive Versus Negative Affect. In Assessing Well-Being: The Collected Works of Ed Diener, ed. Ed Diener, 213-231. Dordrecht: Springer Netherlands.

Flyvbjerg, Bent (ed.). 2014. Megaproject planning and management: Essential readings. Cheltenham: Edward Elgar.

Fornell, Claes, and David F. Larcker. 1981. Evaluating Structural Equation Models with Unobservable Variables and Measurement Error. Journal of Marketing Research (JMR) 18 (1): 39-50.

Gällstedt, Margareta. 2003. Working conditions in projects: Perceptions of stress and motivation among project team members and project managers. International Journal of Project Management 21 (6): 449-455. https://doi.org/10.1016/S0263-7863(02)00098-4.

Gemünden, Hans G., Patrick Lehner, and Alexander Kock. 2018. The project-oriented organization and its contribution to innovation. International Journal of Project Management 36 (1): 147-160. https://doi.org/10.1016/j.ijproman.2017.07.009.

Glaser, Dale N., B. C. Tatum, Delbert M. Nebeker, Richard C. Sorenson, and John R. Aiello. 1999. Workload and Social Support: Effects on Performance and Stress. Human Performance 12 (2): 155-176grap.

Goodman, Richard A., and Lawrence P. Goodman. 1976. Some Management Issues in Temporary Systems: A Study of Professional Development and Manpower-The Theater Case. Administrative Science Quarterly 21 (3): 494. https://doi.org/10.2307/2391857.

Grabher, Gernot. 2010. Cool Projects, Boring Institutions: Temporary Collaboration in Social Context. Regional Studies 36 (3): 205-214. https://doi.org/10.1080/00343400220122025.

Hair, Joe F., Christian M. Ringle, and Marko Sarstedt. 2011. PLS-SEM: Indeed a Silver Bullet. The Journal of Marketing Theory and Practice 19 (2): 139-152. https://doi.org/10.2753/MTP10696679190202.

Hair, J.F., G.T.M. Hult, C.M. Ringle, and M. Sarstedt. 2014. A primer on partial least squares structural equations modeling (PLS-SEM). Los Angeles: Sage.

Hakanen, Jari J., Arnold B. Bakker, and Evangelia Demerouti. 2005. How dentists cope with their job demands and stay engaged: the moderating role of job resources. European Journal of Oral Sciences 113 (6): 479-487. https://doi.org/10.1111/j.1600-0722.2005.00250.x.

Hakanen, Jari J., Wilmar B. Schaufeli, and Kirsi Ahola. 2008. The Job Demands-Resources model: A three-year cross-lagged study of burnout, depression, commitment, and work engagement. Work \& Stress 22 (3): 224-241. https://doi.org/10.1080/02678370802379432. 
Häusser, Jan A., Andreas Mojzisch, Miriam Niesel, and Stefan Schulz-Hardt. 2010. Ten years on: A review of recent research on the Job Demand-Control (-Support) model and psychological wellbeing. Work \& Stress 24 (1): 1-35. https://doi.org/10.1080/02678371003683747.

Haynes, Natasha S., and Peter E.D. Love. 2004. Psychological adjustment and coping among construction project managers. Construction Management and Economics 22 (2): 129-140. https://doi.org/10. 1080/0144619042000201330.

Henseler, Jorg, and Wynne W. Chin. 2010. A Comparison of Approaches for the Analysis of Interaction Effects between Latent Variables Using Partial Least Squares Path Modeling. Structural Equation Modeling: A Multidisciplinary Journal 17 (1): 82-109.

Henseler, J., C. M. Ringle, and R. R. Sinkovics. 2009. The use of partial least squares path modeling in international marketing. In New Challenges to International Marketing, eds. Rudolf R. Sinkovics, Pervez N. Ghauri, 277-319. Bingley et al.: Emerald Group Publishing Limited; Turpin Distribution.

Herzberg, Frederick, Bernard Mausner, and Barbara Bloch Snyderman. 1993. The motivation to work. New Brunswick, N.J., U.S.A.: Transaction Publishers.

$\mathrm{Hu}$, Li-tze, and Peter M. Bentler. 1999. Cutoff criteria for fit indexes in covariance structure analysis: Conventional criteria versus new alternatives. Structural Equation Modeling: A Multidisciplinary Journal 6 (1): 1-55. https://doi.org/10.1080/10705519909540118.

Jarvis, Cheryl B., Scott B. MacKenzie, and Philip M. Podsakoff. 2003. A Critical Review of Construct Indicators and Measurement Model Misspecification in Marketing and Consumer Research. Journal of Consumer Research 30 (2): 199-218. https://doi.org/10.1086/376806.

Karasek, Robert A. 1979. Job Demands, Job Decision Latitude, and Mental Strain: Implications for Job Redesign. Administrative Science Quarterly 24 (2): 285-308.

Kerzner, Harold. 2013. Project Management: A Systems Approach to Planning, Scheduling, and Controlling, Ed. 11. Hoboken, New Jersey: John Wiley \& Sons.

Lavagnon, A.I. 2009. Project success as a topic in project management journals. Project Management Journal 40 (4): 6-19. https://doi.org/10.1002/pmj.20137.

LePine, Jeffrey A., Marcie A. LePine, and Christine L. Jackson. 2004. Challenge and Hindrance Stress: Relationships With Exhaustion, Motivation to Learn, and Learning Performance. Journal of Applied Psychology 89 (5): 883-891. https://doi.org/10.1037/0021-9010.89.5.883.

LePine, Jeffrey A., Nathan P. Podsakoff, and Marcie A. LePine. 2005. A meta-analyric test of the challenge stressor- hindrance stressor framework: an explanation for inconsistent relationships among stressors and performance. Academy of Management Journal 48 (5): 764-775. https://doi. org/10.5465/AMJ.2005.18803921.

MacCallum, Robert C., and Michael W. Browne. 1993. The use of causal indicators in covariance structure models: Some practical issues. Psychological Bulletin 114 (3): 533-541. https://doi.org/10. 1037/0033-2909.114.3.533.

Matsumoto, David Ricky (ed.). 2009. The Cambridge dictionary of psychology, 1. publ. Cambridge u.a.: Cambridge Univ. Press.

Nunnally, Jum C., and Ira H. Bernstein. 1994. Psychometric theory, 3rd ed. New York: McGraw-Hill.

Pearsall, Matthew J., Aleksander P.J. Ellis, and Jordan H. Stein. 2009. Coping with challenge and hindrance stressors in teams: Behavioral, cognitive, and affective outcomes. Organizational Behavior and Human Decision Processes 109 (1): 18-28. https://doi.org/10.1016/j.obhdp.2009.02. 002 .

Peters, Lawrence H., Edward J. O'Connor, and Cathy J. Rudolf. 1980. The behavioral and affective consequences of performance-relevant situational variables. Organizational Behavior and Human Performance 25 (1): 79-96. https://doi.org/10.1016/0030-5073(80)90026-4.

Podsakoff, P.M., and Dennis W. Organ. 1986. Self-Reports in Organizational Research: Problems and Prospects. Journal of Management 12 (4): 531-544. https://doi.org/10.1177/014920638601200408.

Podsakoff, Philip M., Scott B. MacKenzie, Jeong-Yeon Lee, and Nathan P. Podsakoff. 2003. Common method biases in behavioral research: A critical review of the literature and recommended remedies. Journal of Applied Psychology 88 (5): 879-903. https://doi.org/10.1037/0021-9010.88.5.879.

Preacher, Kristopher J., and Ken Kelley. 2011. Effect size measures for mediation models: quantitative strategies for communicating indirect effects. Psychological Methods 16 (2): 93-115. https://doi. org/10.1037/a0022658.

Roe, Robert A., Cary L. Cooper, and Ivan T. Robertson (eds.). 1999. Work performance: A multiple regulation perspective. New York, NY, US: John Wiley \& Sons Ltd.

Rönkkö, Mikko, and Jukka Ylitalo. 2011. PLS marker variable approach to diagnosing and controlling for method variance: Conference Paper. Shanghai. 
Schaufeli, W.B. 2006. The Measurement of Work Engagement With a Short Questionnaire: A CrossNational Study. Educational and Psychological Measurement 66 (4): 701-716. https://doi.org/10. $1177 / 0013164405282471$.

Schaufeli, Wilmar B., and Arnold B. Bakker. 2004. Job demands, job resources, and their relationship with burnout and engagement: a multi-sample study. Journal of Organizational Behavior 25 (3): 293-315.

Schaufeli, Wilmar B., and Toon W. Taris. 2014. A Critical Review of the Job Demands-Resources Model: Implications for Improving Work and Health. In Bridging Occupational, Organizational and Public Health, eds. Georg F. Bauer, Oliver Hämmig, 43-68. Dordrecht: Springer Netherlands.

Schleicher, Deidra J., John D. Watt, and Gary J. Greguras. 2004. Reexamining the job satisfactionperformance relationship: the complexity of attitudes. The Journal of applied psychology 89 (1): 165-177. https://doi.org/10.1037/0021-9010.89.1.165.

Searle, Ben J., and Jaime C. Auton. 2015. The merits of measuring challenge and hindrance appraisals. Anxiety Stress and Coping 28 (2): 121-143. https://doi.org/10.1080/10615806.2014.931378.

Spector, Paul E. 1997. Job satisfaction: Application, assessment, causes, and consequences. Sage.

Sydow, Jörg, Lars Lindkvist, and Robert DeFillippi. 2016. Project-Based Organizations, Embeddedness and Repositories of Knowledge: Editorial. Organization Studies 25 (9): 1475-1489. https://doi.org/ 10.1177/0170840604048162.

Taris, Toon W., and Wilmar B. Schaufeli. 2015. The job demands-resources model. The Wiley Blackwell handbook of the psychology of occupational safety and workplace health: 155-180.

Thamhain, Hans J. 2009. Leadership lessons from managing technology-intensive teams. International Journal of Innovation \& Technology Management 6 (2): 117-133.

Tyssen, Ana K., Andreas Wald, and Patrick Spieth. 2013. Leadership in Temporary Organizations: A Review of Leadership Theories and a Research Agenda. Project Management Journal 44 (6): 52-67. https://doi.org/10.1002/pmj.21380.

van der Doef, Margot, and Stan Maes. 1999. The Job Demand-Control (-Support) Model and psychological well-being: A review of 20 years of empirical research. Work \& Stress 13 (2): 87-114. https://doi.org/10.1080/026783799296084.

Webster, Jennica R., Terry A. Beehr, and Kevin Love. 2011. Extending the challenge-hindrance model of occupational stress: The role of appraisal. Journal of Vocational Behavior 79 (2): 505-516. https:// doi.org/10.1016/j.jvb.2011.02.001

Weigl, Matthias, Severin Hornung, Sharon K. Parker, Raluca Petru, Jürgen Glaser, and Peter Angerer. 2010. Work engagement accumulation of task, social, personal resources: A three-wave structural equation model. Journal of Vocational Behavior 77 (1): 140-153. https://doi.org/10.1016/j.jvb.2010. 03.002 .

Widmer, Pascale S., Norbert K. Semmer, Wolfgang Kälin, Nicola Jacobshagen, and Laurenz L. Meier. 2012. The ambivalence of challenge stressors: Time pressure associated with both negative and positive well-being. Journal of Vocational Behavior 80 (2): 422-433. https://doi.org/10.1016/j.jvb. 2011.09.006.

Williams, L.J., N. Hartman, and F. Cavazotte. 2010. Method Variance and Marker Variables: A Review and Comprehensive CFA Marker Technique. Organizational Research Methods 13 (3): 477-514. https://doi.org/10.1177/1094428110366036.

Xanthopoulou, Despoina, Arnold B. Bakker, Evangelia Demerouti, and Wilmar B. Schaufeli. 2007. The role of personal resources in the job demands-resources model. International Journal of Stress Management 14 (2): 121-141. https://doi.org/10.1037/1072-5245.14.2.121.

Publisher's Note Springer Nature remains neutral with regard to jurisdictional claims in published maps and institutional affiliations. 